\title{
Fetal Pathology Findings Supplemental Qualifiers Dataset
}

National Cancer Institute

\section{Source}

National Cancer Institute. Fetal Pathology Findings Supplemental Qualifiers Dataset. NCI

Thesaurus. Code C147215.

A dataset containing supplemental information, specifically non-standard variables, to parent records in the fetal pathology findings domain. 